\title{
GIÁO DỤC Ý THỨC KHOA HỌC VÀ Ý NGHĨA CỦA NÓ ĐỐI VỚI VIỆC GIÁO DỤC SINH VIÊN ĐẠI HỌC Ở VIỆT NAM HIỆN NAY
}

\author{
PHẠM THI LAN \\ Truờng Đại học Công nghiệp Thành phố Hồ Chi Minh \\ thulandhsp@gmail.com
}

Tóm tắt. Khoa học là một hệ thống tri thức phản ánh những quy luật vận động phát triển của tự nhiên, xã hội và tư duy. Nó bao gồm nhiều môn khoa học cụ thể và có mối quan hệ chặt chẽ với nhau, tác động qua lại với nhau. Là nhân tố làm sáng tỏ vấn đề giáo dục ý thức khoa học, bởi vì giáo dục ý thức khoa học giữ vai trò quan trọng trong hoạt động nhận thức và thực tiễn của con người nói chung và đối với sinh viên nói riêng. Trong bài viêt này, tác giả tập trung luận giải về giáo dục ý thức khoa học trên hai phương diện: 1) Tập trung làm rõ khái niệm và đặc trưng cơ bản của giáo dục ý thức khoa học;2) Đề xuất một số giá trị của việc giáo dục ý thức khoa học đối với sinh viên Đại học ở Việt Nam hiện nay. Tất cả những luận giải đó, xét đển cùng đều hướng đến mục tiêu rèn luyện ý thức khoa học cho sinh viên hiện nay.

Từ khóa. Giáo dục, giáo dục ý thức khoa học, khái niệm, giá trị, sinh viên

\section{EDUCATING SCIENTIFIC AWARENESS AND ITS VALUES FOR EDUCATING THE UNIVERSITY STUDENTS IN VIETNAM TODAY}

\begin{abstract}
Science is a knowledge system that reflects the rules of movement and development of nature, society and thinking. It consists of many specific science subjects and is closely related, interacting with each other. As a factor clatifying the problem of education of scientific consciousness, because It plays an important role in the cognitive and practical activities of people in general and for students in particular. In this article, the author focuses on the explanation of educating scientific awareness in two aspects: 1) Focusing on clarifying the basic concepts and characteristics of educating scientific awareness; 2) proposing some of the values of educating scientific awareness to university students in Vietnam today. All of these interpretations are, after all, We aime to train students' scientific awareness.
\end{abstract}

Keywords. Education, educating scientific awareness, concepts, values, students.

\section{1 ĐẠTT VẤN ĐỀ}

Dưới sự tác động mạnh mẽ của cuộc cách mạng công nghiệp lần thứ 4 đang diễn ra trên tất cả các lĩnh vực của đời sống xã hội. Giáo dục cũng là một trong những vấn đề được quan tâm như đẩy mạnh đào tạo nguồn nhân lực chất lượng cao và đầu tư cho công tác nghiên cứu khoa học là yêu cầu tất yếu nhằm đáp ứng nhu cầu thực tiễn đặt ra. Thực tế cho thấy công tác nghiên cứu khoa học tại các trường Đại học ở Việt Nam còn nhiều hạn chế, chưa khai thác được tiềm năng hiện có . Mặt khác, nền kinh tế thị trường định hướng xã hội chủ nghĩa tại Việt Nam có tính chất hai mặt ảnh hưởng đến giáo dục, đặc biệt là vấn đề giáo dục ý thức khoa học cho sinh viên hiện nay. Do sự vận động và phát triển của hình thái ý thức xã hội sinh viên cũng chịu sự chi phối của quy luật khách quan đó. Những điều đó đã và đang tác động mạnh mẽ vào việc giáo dục ý thức khoa học cho sinh viên các trường Đại học ở Việt Nam hiện nay.

Muốn nhận thức đúng thì phải làm rõ những yếu tố ảnh hưởng tới quá trình giáo dục ý thức khoa học và ý nghĩa của việc giáo dục ý thức khoa học cho sinh viên trường đại học ở Việt Nam hiện nay là điều vô cùng cần thiết. Đây chính là một trong những nhiệm vụ thiết thực để đổi mới mạnh mẽ giáo dục, đào tạo theo hướng "coi trọng phát triển phẩm chất, năng lục của người học".

\section{CÁC KHÁI NIỆM VÀ ĐặC TRỬNG CƠ BẢN}

\subsection{Khái niệm khoa học, ý thức khoa học và giáo dục ý thức khoa học}

\subsubsection{Khái niệm khoa học}

Khoa học là một hiện tượng xã hội được xuất hiện rất sớm trong lịch sử xã hội loài người. Đó là một hình 
thái đặc biệt trong thời kỳ chuyển biến từ chế độ Cộng sản nguyên thủy sang chế độ chiếm hữu nô lệ, khi mà trong xã hội bắt đầu có sự phân công lao động thành lao động chân tay và lao động trí óc.

Tuy là một hiện tượng xã hội xuất hiện rất sớm trong lịch sử nhưng từ ra đời cho đến nay, các quan niệm về bản chất khoa học và phân loại khoa học còn rât khác nhau. Ở đây, chúng tôi chỉ nêu ra một số quan niệm như: Ph.Hêghen khẳng định rằng: "Khoa học thể hiện nhu một vòng tròn này đồng thời cũng là môt vòng tròn của các vòng tròn.... nhũ̃ng vòng khâu của dây chuyền này thể hiện nhũng môn khoa học riêng biệt [5].

Khác Ph.Hêghen nhà triết học duy vật không triệt để Pháp là A.Benrây lại quả quyết rằng: "Khoa hoc, thành quả của nhận thức trí tuệ chỉ dùng để đảm bảo cho chúng ta thực tế chi phối được giới tự nhiên. Nó chỉ cho chúng ta biết cách sư dụng sự vật, nhưng không nói gì về bản chất sụ vật" [5]. Quan niệm này của A.Benrây chỉ nêu ra được một góc độ nào đó về vai trò và tác dụng của khoa học, chứ cũng chưa nêu lên được bản chất của khoa học thậm chí còn phủ nhận cái bản chất của khoa học.

Trong cuốn từ điển triết học do Nxb Tiến bộ, Matxcơva xuất bản bằng tiếng Việt năm 1986, các tác giả cho rằng "khoa học là lĩnh vưc nghiên cúu nhằm muc đích sản xuất ra nhũng tri thức mới về tụ nhiên, xã họi, tư duy bao gồm tất cả nhũ̃ng điều kiện và nhũng yếu tố của sự sản xuất này: nhũ̃ng nhà khoa học, nhüng co quan khoa hoc, nhũng trang bi thực nghiệm, nhüng phương pháp của công tác nghiên cưu, hệ thống khái niệm và phù hợp, hệ thống thông tin khoa học cũng nhu toàn bộ nhũng tri thức hiện có" [11]. Quan niệm này tuy chỉ ra mục đích, cấu trúc và phạm vi tác dụng rộng rãi của khoa học mà bản chất của khoa học chưa được chú ý. Hơn nữa, trong định nghĩa khái niệm "khoa học" mà lại coi "những nhà khoa học", "những cơ quan khoa học, những trang bị thực nghiệm" cũng thuộc về ngoại diện của khái niệm khoa học là điều phải cân nhắc lại. Bởi vì, định nghĩa khái niệm "khoa học" là nêu lên các dấu hiệu thuộc về nội hàm của nó, tức vạch ra cái bản chất mang tính khác biệt của nó. Sự khác biệt ấy chẳng những căn cứ vào nội hàm mà còn căn cứ vào cả ngoại diện nữa. Bởi vì nội hàm và ngoại diên là hai mặt của khái niệm. Chúng có quan hệ biện chứng, thống nhất với nhau, bổ sung cho nhau giúp ta xác định khái niệm. Nhưng cho dù có căn cứ vào ngoại diên đi nữa thì ta vẫn thấy rõ rằng bằng khái niệm "khoa học" khác hẳn với khái niệm đồng nhất hoặc bao hàm. Do đó việc coi "những nhà khoa học", "những cơ quan khoa học", "những trang bị thực nghiệm" cũng thuộc về ngoại diên của khái nệm "khoa học" là chưa có cơ sở chắc chắn.

Còn trong cuốn sách "Một số vần đề nhận thức khoa học" các tác giả đã cho rằng: "Khoa học không chỉ là các tri thức, hệ thống các chân lý khách quan, phản ánh nhũng mối liên hệ cơ bản và nhũng quy luật mà còn là hoạt động của các nhà khoa họ nghiên cứu sản xuất ra những tri thức mói, áp dụng vào thực tiê̂n" [4]. Điều chưa hợp lý ở trong quan niệm này có sự lặp lại về thuật ngữ "chân lý" và "tri thưcc", "những mối liên hệ cơ bản" và "những quy luật". Bởi vì, khi nói đến "chẩn lý đã bao hàm trong đó các tri thức phản ánh đúng đắn hiện thực khách quan và được thực tiễn kiểm nghiệm và khi nói đến những mối quan hệ cơ bản đã nói đến những quy luật. Do đó, sự lặp lại thuật ngữ đó là không cần thiết. Mặt khác, cũng giống như quan niệm về khoa học trong "Tù điển Triết học", trong định nghĩa này các tác giả đã coi "hoạt động của nhũ̃ng nhà khoa học", "nhà nghiên cứu sản xuất, người áp dụng vào thực tiến xã hộ $i$ " là nội dung của khái niệm "khoa học". Điều này cần phải xem xét lại vì những khái niệm đó có nội hàm và ngoại diên khác hẳn với nội hàm và ngoại diên của khái niệm "khoa học".

Tất cả những điều chưa hợp lý ở trên, theo chúng tôi có thể do các tác giả đã chú ý tới khía cạnh lôgíc trong khi đưa ra một định nghĩa chính xác về khoa học. Trong thời gian gần đây, do nhu cầu thực tiễn chúng ta thấy xuất hiện những định nghĩa hợp lý hơn.

Hiện nay, cũng có rất nhiều cách hiểu về khái niệm khoa học xuất phát từ nhiều cách tiếp cận khác nhau. Chúng ta có thể xem xét định nghĩa từ các góc độ sau:

Góc độ thứ nhất: "Khoa họ có thể là một thiết chể xã hội có ý nghĩa nhất định trong xã hội hiện đại. Thiết chế ấy đang làm biến đổi đời sống và số phận con người trên thế giới này hơn bất kỳ một sụ kiện chính trị hoặc tôn giáo nào” [10]

Góc độ thứ hai: Khoa học là "hệ thống tri thức về mọi quy luật của vật chất và sụ vận động của vật chất, nhũ̃ng quy luật của tư nhiên, xã hội, tu duy" [9]

Tuy nhiên, hai định nghĩa mới chỉ đề cập khoa học là hệ thống tri thức, là thiết chế xã hội, mà chưa thấy được nó là hệ thống tri thức chân thực, đúng đắn bao gồm toàn bộ những hiểu biết và đa dạng của con người về thế giới đó, chưa khái quát được những thuộc tính, những quy luật vận động của tự nhiên, xã hội và tư duy. 
Để đưa ra định nghĩa đúng đắn về một khái niệm phản ánh đối tượng nào thì trong đối tượng đó phải có những dấu hiệu bản chất khác biệt nào. Khi đề cập đến khái niệm "khoa học", chính các nhà kinh điển chủ nghĩa Mác - Lênin đã có suy nghĩ như vậy, Chẳng hạn, trong tác phẩm "Biện chứng của tự nhiên". Ănghen đã viết: "Nếu một hình thái vận động này là do tù một hình thái vận động khác phát triển lên thì nhũ̃ng sự phản ánh đó tức là nhũng ngành khoa học khác nhau cũng phải tù̀ một ngành phát triển ra một ngành khác một tất yếu" [1]. Ở luận điểm này ta thấy Ănghen đã coi "nhũng ngành khoa học khác nhau" là sự phản ánh các hình thái vận động khác. Hay nói một cách khái quát hơn, khoa học là sự phản ánh thế giới chứ không phải là bản thân thế giới. Quan điểm này đã được Lênin tiếp thu, phát triển và đã nhiều lần khẳng định rằng: "Khoa hoc... phản ánh bản chất, thực thể của thể giới tư nhiên" hay "Khoa học...bao quát một cách có điều kiện, gần đúng tính quy luật phổ biến của giới tự nhiên vĩnh viến vận động và phát triển" [5]. Từ sự phân tích những định nghĩa về khái niệm "Khoa học" ở trên chúng ta thấy có những đặc trưng bản chất sau đây:

Thư nhất, khoa học với tính cách là hệ thống những tri thức, hình thái ý thức xã hội phản ánh bản chất, thực thể của thế giới tự nhiên, nhưng đồng thời lại ở phía bên ngoài giới tự nhiên. Nghĩa là đối tượng của khoa học là các quy luật của tự nhiên, xã hội và tư duy. Đó là sự phản ánh thế giới chứ không phải là bản thân thế giới đó.

Thư hai, hệ thống tri thức được coi là khoa học bao gồm toàn bộ những hiểu biết và đa dạng của con người về thế giới đó. Đó là các khái niệm, các phạm trù, các quy luật được tập hợp theo một phương pháp chung thống nhất thành một chỉnh thể.

Thư $b a$, hệ thống tri thức được khẳng định là khoa học phải là những tri thức đúng đắn, chân thực. Nghĩa là các tri thức đó phản ánh đúng đắn những hình thức vận động của tự nhiên, xã hội và tư duy. Những tri thức ấy khái quát về thực tiễn và luôn luôn được thực tiển kiểm nghiệm tính chân thực của mình.

Từ những quan niệm như vậy cho phép chúng ta có thể khẳng định rằng: "khoa học là một hệ thống tri thức chân thực phản ánh dưới dạng trùu tượng và khái quát nhũng thuộc tính, nhũng quy luật vận động, phát triển của tự nhiên, xã hội và tư duy".

Quan niệm về khoa học trên đây đã nêu lên được dấu hiệu bản chất và khác biệt của khái niệm khoa học. Nó giúp cho chúng ta có cơ sở để phân biệt được khoa học và các hình thái xã hội khác, đồng thời, nó tránh được những hạn chế khi định nghĩa khái niệm "khoa học". Mặt khác, việc quan niệm của khoa học như vậy cũng tạo ra tiêu chuẩn để kiểm định những khái niệm mới, những phương pháp mới và những lý thuyết mới được hình thành trong quá trình giáo dục ý thức khoa học, vì vậy quan niệm đó góp phần định hướng cho việc hình thành các tri thức khoa học mới trong quá trình giáo dục ấy. Chính vì những lý do đấy, mà chúng tôi sử dụng định nghĩa khoa học đã nêu ra ở trên để nghiên cứu giáo dục ý thức khoa học.

\subsubsection{Khái niệm ý thức khoa học}

Trong lịch sử triết học, chủ nghĩa duy tâm quan niệm ý thức là một thể độc lập, là thực tại duy nhất. Từ đó cường điệu ý thức đến mức coi ý thức không phải là sự phản ánh của vật chất mà là cái sinh ra vật chất. Còn các nhà triết học duy vật đều thừa nhận vật chất tồn tại khách quan và ý thức là sự phản ánh sự vật đó. Tuy nhiên, do ảnh hưởng bởi quan niệm siêu hình, máy móc nên họ đã coi ý thức là sự phản ánh sự vật một cách thụ động, giản đơn, máy móc mà không thấy được tính năng động sáng tạo của ý thức, tính biện chứng của quá trình phản ánh.

Ý thức là sự phản ánh có tính chất năng động, sáng tạo của bộ óc người về thế giới khách quan; là hình ảnh chủ quan của thế giới khách quan. Tính chất phản ánh năng động, sáng tạo của ý thức được thể hiện ở khả năng hoạt động tâm sinh lý của con người trong việc định hướng tiếp nhận, chọn lọc, xử lý và lưu giữ thông tin. Trên cơ sở những thông tin đã có nó có thể tạo ra những thông tin mới và phát hiện ý nghĩa của thông tin được tiếp nhận. Tính chất năng động sáng tạo của sự phản ánh ý thức còn được thể hiện ở quá trình con người tạo ra những ý tưởng, giả thuyết, huyền thoại, v.v. trong đời sống tinh thần của mình hoặc khái quát bản chất, quy luật khách quan, xây dựng các mô hình tư tưởng, tri thức trong các hoạt động của con người.

Ý thức là hình ảnh chủ quan của thế giới khách quan. Đó là hình ảnh về thế giới khách quan, hình ảnh ấy bị thế giới khách quan quy định cả về nội dung và hình thức biểu hiện, nhưng nó không còn y nguyên 
như thế giới khách quan mà nó đã cải biến thông qua lăng kính chủ quan (tâm tư, tình cảm, nguyện vọng, kinh nghiệm, tri thức, nhu cầu, v.v.). Theo Mác, ý thức "chẳng qua chỉ là vật chất được đem chuyển vào trong đầu óc con người và được cải biến đi trong đó” [8].

Y thức là một hiện tượng xã hội. Sự ra đời, tồn tại của ý thức gắn liền với thực tiễn, chịu sự chi phối không chỉ các quy luật sinh học mà chủ yếu là quy luật xã hội, do nhu cầu giao tiếp xã hội và các điều kiện sinh hoạt hiện thực của con người quy định. Với tính năng động, ý thức đã sáng tạo lại hiện thực theo nhu cầu của thực tiễn xã hội.

Ý thức được thể hiện qua hai hình thức: ý thức thông thường và ý thức khoa học. Về khái niệm ý thức khoa học, có nhiều nhà nghiên cứu đề cập đến. Chẳng hạn như trong cuốn sách Tập bài giảng Triết học Mác Lênin, tác giả Mai Văn Bính đã đưa ra quan niệm: "Ý thức khoa học là một hình thái đặc biệt của ý thức xã hội, phản ánh sự vận động và phát triển của tụ nhiên, xã hội và tu duy bằng hệ thống các khái niệm, quy luật, lý thuyết, trìu tương". [3]. Hoặc "Ý thức khoa học vì̀a là một hình thái ý thức xã hội, vìa là một hiện tượng xã hội đặc biệt, xem xét nó nhu một hình thái ý thức xã hội không được tách rời, xem xét nhu là một hiện tuợng xã họi. Ý thức khoa học (với tu cách là một hình thái ý thức xã hội), là hệ thống tri thức phản ánh chân thực dưới dạng lôgíc trìu tương về thế giới đãa được kiểm nghiệm qua thực tiễn. Ý thức khoa học mang đặc điểm chung của hình thái ý thức xã hội đều là sản phẩm của tồn tại, phản ánh tồn tại, do tồn tại xã họi quy định" [7].

Tiếp thu những ưu thế và nhược điểm trong các quan điểm trên, theo chúng tôi có thể đưa ra một định nghĩa khái quát như sau: "Ý thức khoa học là sự phản ánh hiện thực khách quan để sáng tạo nên hệ thống tri thức đúng đằn về nhüng quy luật của tự nhiên, xã hội và tu duy nhằm hình thành niềm tin, tình cảm, ý chi và lý tưởng khoa học cho con người”.

Những quan niệm đã trình bày ở trên về ý thức khoa học có ưu điểm như: một là, đã coi ý thức khoa học là một dạng cụ thể của các hình thái ý thức xã hội; hai là, xem ý thức khoa học có thể tồn tại dưới dạng hệ thống chung nhất, biểu hiện thành các khái niệm, phạm trù, quy luật hoặc dưới dạng cụ thể là các tri thức chuyên ngành; ba là, những tri thức khoa học là những tri thức chân thực, phản ánh đúng đắn hiện thực khách quan và được thực tiễn kiểm nghiệm.

Tuy nhiên, các khái niệm về ý thức khoa học trên còn có một số hạn chế nhất định. Mặc dù các tác giả đã xác định được ý thức khoa học phản ánh hiện thực khách quan một cách trừu tượng, bằng các khái niệm, phạm trù, quy luật, nhưng, nhìn chung, khái niệm đó chưa chỉ ra được cấu trúc và vai trò của ý thức khoa học.

Kế thừa những ưu điểm và khắc phục những hạn chế trong các quan niệm đó, chúng tôi đưa ra định nghĩa khái quát như sau: Ý thức khoa học là sự phản ánh một cách khái quát hóa, trùu tuợng hóa về tụ nhiên, xã hội và tu duy, và được thực tiễn kiểm nghiệm, qua đó hình thành niềm tin, tình cảm, ý chí và lý tưởng khoa họ cho con người.

Như vậy, ý thức khoa học có sự khác biệt so với ý thức các hình thái ý thức xã hội khác ở chỗ: Một là, phạm vi phản ánh của ý thức khoa học rất rộng lớn, bao quát toàn bộ thế giới khách quan trong khi các hình thái ý thức xã hội khác chỉ phản ánh một mặt, mỗi khía cạnh nào đó của đời sống xã hội. Hai là, ý thức khoa học có thể tồn tại dưới dạng hệ thống lý luận chung nhất hoặc dưới dạng cụ thể là các tri thức chuyên ngành. Ba là, những tri thức của khoa học là những tri thức chân thực, phản ánh đúng đắn khách quan và được thực tiễn kiểm nghiệm. Bốn là, ý thức khoa học phản ánh hiện thực khách quan một cách trừu tượng bằng các khái niệm, phạm trù, quy luật, là ngôn ngữ được chuyên môn hóa, là công cụ của tư duy khoa học. Năm là, ý thức khoa học giữ vị trí quan trọng trong sự nhận thức hiện thực, là cơ sở nhận thức cho các hình thái ý thức xã hội khác trong quá trình phản ánh hiện thực. Nhờ có tri thức, con người không ngừng vươn tới cái mới, sáng tạo ra một thế giới mới, ngày càng vươn lên làm chủ tự nhiên, làm chủ xã hội và làm chủ chính bản thân mình. Sáu là, xét về vai trò, ý thức khoa học vạch ra những quy luật, phương hướng và phương pháp chung nhất và phương pháp cụ thể để đáp ứng hoạt động cải biến tự nhiên và xã hội của con người. Bảy là, với tư cách là một thiết chế xã hội, khoa học đã thâm nhập vào mọi lĩnh vực hoạt động xã hội và thực hiện những chức năng của một thiết chế xã hội đó là định ra một khuôn mẫu hành vi, lấy tính khoa học làm thước đo. Tăng hàm lượng khoa học trong công nghệ và sản phẩm nhằm tạo thế mạnh cạnh tranh cho sản phẩm. Khoa học ngày càng trở thành một phương tiện góp phần làm biến đổi tận gốc rễ mọi mặt của đời sống xã hội.

Vì vậy, việc nhìn nhận khoa học là một thiết chế xã hội có ý nghĩa quan trọng đối với người nghiên 
cứu, đồng thời cũng có ý nghĩa quan trọng liên quan đến việc hoạch định chính sách, hỗ trợ những nghiên cứu, có ý nghĩa thiết thực cho sự phát triển xã hội và đặc biệt là giáo dục ý thức khoa học cho sinh viên.

\subsubsection{Khái niệm giáo dục ý thức khoa học}

Nước ta đang trong quá trình hội nhập quốc tế ngày càng sâu rộng; sự phát triển nhanh chóng của khoa học và công nghệ, khoa học giáo dục và sự cạnh tranh quyết liệt trên nhiều lĩnh vực giữa các quốc gia đòi hỏi giáo dục phải đổi mới. Thực chất cạnh tranh giữa các quốc gia hiện nay là cạnh tranh về nguồn nhân lực và về khoa học và công nghệ. Xu thế chung của thế giới khi bước vào thế kỷ XXI là tiến hành đổi mới mạnh mẽ hay cải cách giáo dục. Trước thực tế trên, Nghị quyết Đại hội Đảng toàn quốc lần thứ XI đã xác định: "Đổi mới căn bản, toàn diện nền giáo dục theo huoơng chuẩn hóa, hiện đại hóa, xã hội hóa, dân chủ hóa và hội nhập quốc tế" và "Phát triển nhanh nguồn nhân lực, nhất là nguồn nhân lực chất lương cao, tập trung vào việc đổi mới căn bản và toàn diện nền giáo dục quốc dân” [2].

Tăng cường nghiên cứu khoa học và chuyển giao công nghệ của các cơ sở giáo dục đại học; gắn kết giữa đào tạo và nghiên cứu, giữa các cơ sở đào tạo với các cơ sở sản xuất kinh doanh. Ưu tiên đầu tư nghiên cứu các khoa học mũi nhọn, phòng thì nghiệm trọng điểm, phòng thí nghiệm chuyên ngành, trung tâm công nghệ cao, cơ sở sản xuất thử nghiệm hiện đại một số cơ sở giáo dục đại học. Có chính sách khuyến khích sinh viên nghiên cứu khoa học. Để đạt được hiệu quả đó thì điều quan trọng phải nắm vững kiến thức. Có như vậy, mới thực hiện được các hoạt động nghiên cứu và phát triển về tư duy khoa học. Việc nắm vững hoạt động nghiên cứu khoa học không chỉ có ý nghĩa đối với các nhà nghiên cứu mà còn có ý nghĩa đối với sinh viên khi tham gia vào hoạt động giáo dục ý thức khoa học. Có rất nhiều quan niệm được đưa ra về giáo dục ý thức như:

Có ý kiến cho rằng: Giáo dục ý thức là hiện tượng xã hội đặc biệt, bản chất của nó là sư truyền đạt và lĩnh hội kinh nghiệm lịch sủ - xã hội của các thế hệ loài ngườ phản ánh hiện thực một cách khách quan tự nhiên, xã hội và tu duy.

Quan niệm khác lại hiểu: Giáo dục ý thức khoa học là hoạt động chuyên môn của xã hội loài người, làm hình thành và phát triển nhân cách cho người được giáo dục theo nhũng yêu cầu của xã họi trong tùng giai đoạn cu thể.

Một quan niệm khác lại cho rằng: Giáo dục ý thưc khoa học là quá trình tổ chưc, có ý thức, huớng tới muc địch khơi gợi hoặc biến đổi nhận thức, năng lực, tình cảm, thái độ của nguời dạy và người học theo huớng tích cực. Nghĩa là góp phần hoàn thiện nhân cách người học bằng nhũng tác động có ý thức tùu bên ngoài, góp phần đáp úng các nhu cầu tồn tại và phát triển của con nguời trong xã hội.

Uu điểm của các quan niệm trên: đã nêu bật được giáo dục ý thức khoa học là hướng đến sự hình thành và phát triển nhân cách. Làm biến đổi nhận thức trong tình cảm và thái độ của người học. Nhược điểm: chưa hiểu được giáo dục ý thức khoa học là sự tương tác giữa thầy và trò. Từ sự phân tích ưu và nhược điểm trên, chúng tôi đưa ra định nghĩa chung nhất về giáo dục ý thức khoa học như sau: "Giáo dục $\dot{y}$ thức khoa hoc là sự tương tác giữa thầy và trò nhằm giúp cho học trò có thể tiếp nhận được các tri thức khoa hoc, trên cơ sở hình thành niềm tin, tình cảm, ý chí và lý tường khoa hoc cho họ”.

\section{2. Đặc trưng co bản của giáo dục ý thức khoa học}

Giáo dục ý thức khoa học là một hiện tượng tâm lý xã hội. Nó có rất nhiều cách tiếp cận khác nhau. Nếu xét về mặt cấu trúc thì giáo dục ý thức khoa học có cấu trúc phức tạp, bao gồm nhiều bộ phận khác nhau đó là giáo dục tri thức khoa học, giáo dục niềm tin khoa học, giáo dục tình cảm khoa học, giáo dục ý chí khoa học và giáo dục lý tưởng khoa học.

\section{- Giáo dục tri thúc khoa học}

Trong bối cảnh toàn cầu hóa và nền kinh tế tri thức có sự ảnh hưởng mạnh mẽ làm cho thế giới có nhiều biến đổi sâu sắc. Bên cạnh đó cùng với sự phát triển mạng viễn thông đã cho phép trao đổi, truyền tải thông tin một cách nhanh chóng. Con người tiếp cận được với tri thức nhân loại. Việc tiếp cận tri thức nên coi trọng trong việc truyền thụ tri thức khoa học đến với sinh viên bằng cách thông qua một số hình thức giáo dục như:

* Truyền thu tri thúc kinh nghiệm cho sinh viên.

Nhờ có tri thức kinh nghiệm sinh viên có được những hình dung về các sự vật, hiện tượng. Giúp sinh viên giải quyết được những vấn đề tự nhiên và xã hội. Những tri thức kinh nghiệm ngày càng được hphát triển 
đa dạng, phong phú và là cơ sở cho sự hình thành tri thức khoa học. Tuy nhiên, tri thức kinh nghiệm chỉ giúp cho sinh viên phát triển đến một khuôn khổ nhất định, không thể vượt khỏi những giới hạn về mặt sinh học về chính bản thân mình.

* Truyền thu tri thức khoa hoc cho sinh viên.

Tri thức khoa học là những hiểu biết được tích lũy một cách có hệ thống nhờ hoạt động nghiên cứu khoa học, được vạch sẵn theo một kế hoạch, có mục tiêu xác định và được tiến hành dựa trên một hệ thống phương pháp khoa học. Khi truyền thụ tri thức phải phân biệt cho sinh viên hiểu được sự khác nhau cơ bản giữa tri thức kinh nghiệm và tri thức khoa học. Từ việc truyền thụ tri thức khoa học đã làm hình thành ở mỗi sinh viên một hệ thống tri thức khoa học, những kỹ năng vận dụng linh hoạt, sáng tạo để giải quyết các vấn đề do thực tiễn xã hội đặt ra.

\section{- Giáo dục niềm tin khoa học}

Niềm tin khoa học được xem như là một động lực thúc đẩy con người trong quá trình hoạt động và lĩnh hội tri thức. Nhận thức đúng bản chất niềm tin khoa học sẽ quyết định đến sự hình thành ý thức của mỗi sinh viên. Niềm tin khoa học là nhân tố đảm bảo cho sinh viên trở thành lực lượng quan trọng trong sự phát triển của xã hội. Giáo dục niềm tin khoa học cho sinh viên các trường Đại học ở Việt Nam hiện nay là một yêu cầu rất cần thiết. Để làm được điều đó, cần phải trang bị đầy đủ về thế giới quan, phương pháp luận giúp sinh viên nhận thức đúng đắn về nội dung và hình thức của vấn đề.

Đa dạng hóa các hoạt động mang tính tích cực để sinh viên được tham gia vào quá trình học tập, rèn luyện đạo đức và nắm vững quá trình giáo dục niềm tin. Giúp sinh viên nhận thức nếu muốn thành công phải dựa vào chính bản thân họ, chứ không phải có tính chất may rủi, ngẫu nhiên gắn liền với "số phận" của bản thân mang đến. Niềm tin khoa học vững chắc bao nhiêu thì ý chí bảo vệ những quan điểm của mình càng sâu sắc bấy nhiêu. Chính niềm tin khoa học ấy, tạo cho sinh viên sức mạnh vượt qua mọi khó khăn trong cuộc sống.

\section{- Giáo duc tình cảm khoa hoc}

Tình cảm là những rung động, biểu hiện thái độ của con người trong các mối quan hệ. Tình cảm khoa học, là một hình thái đặc biệt của sự phản ánh hiện thực, được hình thành từ sự khái quát những cảm xúc cụ thể của con người khi nhận sự tác động của ngoại cảnh tùy vào từng đối tượng nhận thức và sự rung động của con người về đối tượng đó. Trong các quan hệ đó hình thành nên các loại tình cảm khác nhau, như tình cảm đạo đức, tình cảm thẩm mỹ, tình cảm trí tuệ, tình cảm hoạt động thực tiễn v.v.. Tình cảm đạo đức biểu thị thái độ của con người đối với yêu cầu đạo đức xã hội, trong mối quan hệ đối với những người khác, đối với tập thể và đối với trách nhiệm xã hội của bản thân. Tình cảm trí tuệ biểu thị thái độ của con người đối với suy nghĩ, tư tưởng, các nhu cầu nhận thức gồm sự hiểu biết, sự hài lòng, sự hoài nghi. Tình cảm thẩm mỹ là thái độ rung cảm của con người đối với cái đẹp trong tự nhiên, xã hội, trong nghệ thuật và văn học. Tình cảm hành động thực tiễn là thể hiện thái độ của con người đối với hành động liên quan đến sự thỏa mãn hay không thỏa mãn nhu cầu thực hiện hành động đó.

Việc giáo dục tình cảm khoa học đối với sinh viên trong giai đoạn hiện nay, cần có sự phối hợp giữa gia đình, nhà trường và xã hội. Giáo dục tình cảm khoa học là yếu tố nền tảng đảm bảo cho sự tồn tại và phát triển của mỗi con người trong xã hội. Hiện nay, các trường Đại học nên xây dựng môi trường giáo dục toàn diện, thân thiện và gắn với nội dung bài học hoặc thông qua các cuộc vận động, phong trào thi đua $v$. v.. Mục đích hướng sinh viên vào việc rèn luyện ý thức đạo đức và sống có trách nhiệm đối với chính bản thân và sống vì người khác.

\section{- Giáo dục ý chí khoa học}

V.I.Lênin cho rằng: "'y chi là một trong nhũng yếu tố tạo nên sự nghiệp cách mang của hàng triệu người trong cuộc đấu tranh giai cấp quyết liệt nhằm giải phóng mình, giải phóng nhân loại" [6]

Ý chí khoa học là những phẩm chất tâm lý của một cá nhân. Ý chí khoa học được xem là mặt năng động của ý thức, nó được biểu hiện cụ thể trong thực tiền. Ý chí khoa học là tâm lý điểu chỉnh, điều khiển hành vi tích cực trong việc giải quyết những vấn đề đặt ra. Trong hoạt động học tập thì xúc cảm có vai trò như là một sự điều chỉnh tăng cường, kích thích tính tích cực về mặt tâm lý của sinh viên. Phải định hướng cho sinh viên sống vì mục tiêu và biết quý trọng cuộc sống. Trong cuộc sống có rất nhiều khó khăn mà chúng ta phải vượt qua như một quy luật của tự nhiên. Chính vì vậy, nên giáo dục thêm đức tính kiên trì, bền bỉ cho sinh viên là cần thiết. Chỉ có lòng kiên định và sự kiên trì, bền bỉ mới có thể vượt qua được 
những trở ngại của cuộc sống. Chủ tịch Hồ Chí Minh đã dạy: "Không có việc gì khó - Chỉ sợ lòng không bền - Đào núi và lấp biển - Quyết chi ắt làm nên". Chỉ cần có ý chí là sinh viên có thể vượt qua mọi khó khăn dù nó có lớn đến mức độ nào. Từ đó, giúp sinh viên tìm ra những phương pháp hiệu quả nhất để tự hoàn thiện bản thân trong cuộc sống.

\section{•Giáo dục lý tưởng khoa hoc}

Giáo dục lý tưởng khoa học là hoạt động tổng thể tác động đến chính bản thân sinh viên. Việc giáo dục lý tưởng khoa học cho sinh viên phải luôn quan tâm đến việc phát hiện, bồi dưỡng và tôn vinh những sinh viên điển hình "sinh viên tiên tiến làm theo lời Bác", tiếp tục nhân rộng những tấm gương điển hình với hiệu ứng "mắt xích" nhiều cá nhân tốt, tạo ra thế hệ "là chủ nhân tuoơng lai của nước nhà".

Giáo dục lý tưởng khoa học cho sinh viên được xem như "ánh sáng mặt trời với sự sống”. Sinh viên sợ nhất là "sụ trống rỗng tâm hồn". Vì vậy, nên định hướng cho sinh viên hiểu sống phải luôn có lý tưởng. Như Chủ tịch Hồ Chí Minh dặn dò toàn Đảng, toàn dân ta: "Bồi duỡng thế hệ cách mạng cho đời sau là một việc rất quan trọng và cần thiết”. Nắm vững lời dạy của Bác, sinh viên hiện nay tiếp tục hoàn thành trách nhiệm của mình. Không quên đi quá khứ hào hùng của cha anh ta bởi "Tượng đài vinh quang Việt Nam" được xây lên từ máu xương thế hệ cha anh, tất cả vì một Việt Nam trọn vẹn, độc lập, tự do và hạnh phúc. Một số người cho rằng, việc giáo dục lý tưởng khoa học cho sinh viên là Cú lo đủ việc làm, chăm sóc no đủ là sinh viên sống tốt ngay. Quan điểm như thế là không đúng. Do vậy phải định hướng để sinh viên đủ lòng tin, niềm tin vào tương lai do họ tự tạo ra.

Lý tưởng khoa học không chỉ được xây dựng nên những ước mơ và hoài bão mà còn phải dựa trên nền tảng nhân sinh quan, nhân sinh quan khác nhau sẽ hình thành lý tưởng khoa học khác nhau, ứng với các mục đích khác nhau. Giúp sinh viên hiểu được lý tưởng khoa học có những ước mơ sống cao đẹp được xây dựng trên cơ sở vững chắc về đạo làm người. Ngày nay, đất nước đã độc lập, giang sơn liền một dãy thì lý tưởng cao đẹp đối với sinh viên phải chăng là học thành tài, có cơ hội để cống hiến nhiều hơn, xứng đáng với những gì mà thế hệ đi trước đã khẳng định. Không ai cho phép mình đứng ngoài cuộc, tách mình khỏi cuộc sống đã và đang vận động.

\section{3. Ý NGHĨA CỦA VIỆC GIÁO DỰ Ý THỨC KHOA HỌC CHO SINH VIÊN CÁC TRƯỜNG ĐẠI HỌC Ở VIÊTT NAM HIỆN NAY}

Bác Hồ đã dạy: "Muốn xây dựng chủ nghĩa xã hội, phải có con người xã hội chủ nghĩa". Việc giáo dục ý thức khoa học cho sinh viên các trường Đại học là một trong những nội dung mang ý nghĩa thiết thực tạo nên những con người mới, nguồn nhân lực trong sự nghiệp công nghiệp hóa, hiện đại hóa đất nước. Sau đây tác giả xin có một vài kiến nghị về giá trị của việc giáo dục ý thức khoa học như sau:

Một là: Giúp sinh viên tụ hình thành nhân cách của chính bản thân mình. Nó chỉ được hình thành và phát triển trong quá trình hoạt động, giao tiếp mà giáo dục là yếu tố chủ đạo. Giáo dục ý thức khoa học có chức năng như mọi lĩnh vực giáo dục khác đóng vai trò hết sức to lớn đối với sự hình thành và phát triển nhân cách sinh viên. Thông qua giáo dục ý thức khoa học nội dung các phạm trù, nguyên tắc, chuẩn mực đạo đức được nhận thức và hình thành. Giáo dục ý thức khoa học là cơ sở để sinh viên tiếp nhận những giá trị đạo đức truyền thống tốt đẹp của quê hương, dân tộc.Từ đó, củng cố phát triển tinh thần yêu nước và lòng tự hào đối với quê hương. Hướng sinh viên đến việc có trách nhiệm trong học tập, nghiên cứu khoa học, hoạt động xã hội góp phần xây dựng quê hương ngày một giàu đẹp hơn.

Đặc biệt, phải giúp cho sinh viên thấy rõ được sự cần thiết trong việc phát triển phong trào học tập, rèn luyện vì sự nghiệp "dân giàu, nước mạnh, xã hội công bằng, dân chủ văn minh". Khuyến khích hỗ trợ sinh viên tham gia vào các sinh hoạt truyền thống, tổ chức du khảo về nguồn, tổ chức phong trào đền ơn đáp nghĩa, tổ chức "tiếp lửa truyền thống - mãi mãi tuổi 20", "Thanh niên tình nguyện", diễn đàn "tuổi trẻ sống đẹp sống có ích, học tập và hưởng ứng làm theo gương anh hung cách mạng "Nguyễn Văn Thạc" và "Đặng Thùy Trâm".

Hai là: Ý thức được việc tu duoõng và rèn luyện ở sinh viên. Vấn đề giáo dục ý thức khoa học cho sinh viên các trường Đại học trong những năm qua đã có những chuyển biển tích cực. Sự chuyển biến đó đã tạo điều kiện cho việc tu dưỡng, rèn luyện về giáo dục ý thức khoa học của sinh viên ở nhận thức mới hơn.

Kết hợp đồng bộ giữa các bộ phận trong và ngoài nhà trường với việc nâng cao giáo dục ý thức khoa 
học. Nhà trường giữ vai trò là trung tâm trong quá trình giáo dục ý thức. Giáo dục ý thức khoa học tác động vào sự phát triển bền vững của một xã hội. Nắm vững giáo dục ý thức khoa học nhằm góp phần củng cố và tiếp thu những giá trị mới tạo điều kiện cho sự phát triển của xã hội.

Thấm nhuần việc nắm vững mục tiều và định hướng giáo dục tư tưởng chính trị dựa trên nền tảng chủ nghĩa Mác- Lênin và tư tưởng Hồ Chí Minh, đường lối chính sách của Đảng và pháp luật nhà nước về đường lối đổi mới, kiên trì mục tiêu độc lập dân tộc và chủ nghĩa xã hội thì vấn đề đặt ra là sinh viên phải tự đổi mới chính bản thân mình cho phù hợp với những chuẩn mực của xã hội yêu cầu. Việc củng cố tri thức lý luận, bổ sung các tri thức còn thiếu, góp phần quan trọng trong việc tu dưỡng và tự ý thức ở mỗi sinh viên.

Ba là: Hình thành kỹ năng, lối sống khoa hoc ở sinh viên. Sinh viên là những người đang trong giai đoạn chuyển từ sống phụ thuộc sang độc lập. Chúng ta nên trang bị kỹ năng sống để giúp sinh viên vững tin bước vào cuộc sống. Đây là một trong những kỹ năng quan trọng giúp sinh viên đánh giá đúng về bản thân mình, để có thể biết được mình là ai, mình có những điểm mạnh yếu gì trong việc lựa chọn những giá trị phù hợp. Giúp sinh viên có cơ sở để tự hoàn thiện bản thân mình.

Đẩy mạnh phong trào thi đua của sinh viên và giảng viên trong việc xây dựng môi trường trong sạch, lành mạnh như: nề nếp kỷ luật, nề nếp ăn nghỉ, sinh hoạt tại ký túc xá, quy định phong cách ứng xử, tạo nên nét đẹp truyền thống của từng trường, ngoài ra các trường cần phối hợp với cơ quan như bài trừ tệ nạn ma túy, mại dâm, cờ bạc, gian lận trong thi cử, lối sống lai căng thực dụng, văn hóa phẩm không lành mạnh... có như vậy mới giúp cho sinh viên ý thức việc chống lại các hiện tượng tiêu cực trong xã hội như hiện nay.

Bốn là: Đem lại nhũng giá trị về cảm thu văn hóa - thẩm mỹ. Nội dung của giáo dục văn hóa ở trường Đại học là hình thành cho sinh viên nét lịch sự trong quan hệ giao tiếp với mọi người, hành vi ứng xử mang tính văn hóa trong các mối quan hệ với nhau. Giáo dục cho sinh viên biết cảm thụ cái đẹp trong tự nhiên, cuộc sống và trong nghệ thuật, đánh giá chân - thiện - mỹ về bản thân và người khác. Đây mặc dù không phải là toàn bộ hệ thống ý nghĩa, nhưng đó là ý nghĩa đầu tiên, là điểm khỏi đầu và cũng là mốc cao nhất để giáo dục ý thức khoa học cho sinh viên, nhằm tạo ra những con người mới đầy đủ cả năng lực và phẩm chất, góp phần đem lại sự phồn vinh và phát triển đất nước.

Đấy mạnh việc giáo chủ nghĩa yêu nước, tinh thần đoàn kết, tương thân tương ái, tính cố kết cộng đồng v.v hướng dẫn sinh viên hướng tới các giá trị chân - thiện - mỹ, phấn đấu cho tương lai của chính bản thân mình. Kiên quyết lên án và bài trừ các thói hư, tật xấu, đấu tranh với những biểu hiện tiêu cực, tham nhũng, quan liêu, vô trách nhiệm, coi thường kỷ cương phép nước. Đề cao nhân rộng những tấm gương tốt đẹp trở thành một lối sống khoa học lành mạnh trong xã hội.

Năm là, khuyến khich nhüng công trình nghiên cưu khoa học của sinh viên

Phải xem trọng công tác nghiên cứu khoa học của sinh viên là một nội dung đào tạo quan trọng nhằm phát huy trí tưởng tượng và sự sáng tạo. Đẩy mạnh công tác nghiên cứu khoa học ở sinh viên giúp cho họ luôn đổi mới về tri thức khoa học.

Nên trang bị đầy đủ về vai trò, trách nhiệm của sinh viên trong các hoạt động nghiên cứu khoa học, với những hình thức và mức độ khác nhau như làm bài tập nghiên cứu, tiểu luận, khóa luận tốt nghiệp v.v.. Tổ chức rèn luyện cho sinh viên nắm vững các kỹ năng nghiên cứu khoa học. Hay tham gia các hội nghị chuyên đề về quản lý hoạt động nghiên cứu khoa học đối với sinh viên.

Thành lập câu lạc bộ nhằm tổ chức nghiên cứu những công trình khoa học cấp Khoa. Thông qua các câu lạc bộ sinh viên được tham gia học tập, trao đổi kinh nghiệm và phương pháp tiếp cận khoa học. Hoạt động này sẽ kích thích được nhu cầu và hứng thú nghiên cứu khoa học ở sinh viên. Mặt khác, nó còn giúp cho các cấp quản lý khi triển khai kế hoạch hoạt động tổ chức nghiên cứu và đánh giá kết quả nghiên cứu một cách đầy đủ hơn.

\section{KẾT LUẬN}

Trong bối cảnh hiện nay, chưa bao giờ vấn đề tiếp nhận các tri thức khoa học để hình thành niềm tin khoa học, tình cảm khoa học, ý chí khoa học và lý tưởng khoa học cho sinh viên lại nhận được nhiều sự quan tâm như hiện nay. Việc giáo dục ý thức khoa học đã tạo ra một môi trường thuận lợi để sinh viên học tập và phát triển. Hình thành những niềm tin tích cực, đúng đắn với những giá trị tốt đẹp của cuộc sống.

Kinh tế thị trường trong quá trình hội nhập quốc tế tạo ra những giá trị mới về năng lực và sự sáng tạo 
của mỗi cá nhân. Chính những giá trị này đang tác động mạnh mẽ đến niềm tin và lối sống của sinh viên. Tạo cơ sở cho những suy nghĩ độc lập, thực tế, có ý chí phấn đấu vươn lên, tự khẳng định mình và tìm kiếm những cơ hội phát triển cho bản thân. Góp phần hướng tới việc xây dựng xã hội công bằng và ngày càng tiến bộ hơn.

\section{TÀI LIỆU THAM KHẢO}

1. Ph.Ăngghen (1963), Biện chứng tự nhiên, Nxb Sự thật, Hà Nội

2. Bộ Giáo dục và Đào tạo (2013), Hỏi - Đáp về một số nội dung đổi mới căn bản, toàn diện giáo dục và đào tạo", Nxb Giáo dục Việt Nam

3. Mai Văn Bính (2009), "Tập bài giảng Triết học Mác - Lênin”, Nxb Đại học Sư phạm.

4. Trịnh Thu Hương (1993) Một số vấn đề về nhận thức khoa học, Nxb Đại học Sư phạm Hà Nội.

5. V.I.Lênin (1981), Toàn tập, tập 29, Nxb Tiến bộ, Matxcơva.

6. V.I Lênin (1997), Toàn tập, tập 41, Nxb Tiến bộ Matxcơva.

7. Đinh Thiên Lương (2010), "Tập bài giảng Triết học Mác - Lênin”, Nxb Lao động - Xã hội.

8. C.Mác và Ănghen (1994), Toàn tập, tập 20, Nxb Chính trị Quốc gia, Hà Nội.

9. Pierre Auger: (1961) Tendensces actuelles de la recherche scientifique, UNESCO, Paris

10. Price Derek J., The Nature of Science. Pp 1-28 in supplement to Biology, by Goldsby. New York: Harper \& Row

11. “Từ điển Triết học" (1986), Nxb Tiến bộ Matxcơva.

Ngày nhận bài: 23/10/2019

Ngày chấp nhận đăng: 23/12/2019 